\title{
Valoración del silencio del imputado en el proceso penal. Derecho alemán y derecho chileno
}

\author{
Carlos Correa Robles*
}

\begin{abstract}
RESUMEN
El presente trabajo propone un análisis jurídico del silencio del imputado en el proceso penal, desde un punto de vista comparado. Para ello se analiza en primer término el sistema alemán, donde la doctrina y la jurisprudencia han discutido intensamente el valor probatorio del silencio total, parcial y temporal del imputado. En segundo lugar, el trabajo examina el modelo chileno adoptado tras la promulgación del Código Procesal Penal en el año 2000.
\end{abstract}

Proceso penal - silencio del imputado - nemo tenetur

\section{Probative value of the accused's silence. German and cbilean law}

\begin{abstract}
This work analyses the accused's silence in criminal procedures, from a comparative perspective. First of all, is the German system to be analyzed, given that scholarship and the courts bave intensely discussed about the probative value of the accused's total, partial and temporary silence. Secondly, is the Chilean model adopted after the promulgation in the year 2000 of the Code of Criminal Procedure to be discussed.
\end{abstract}

Criminal proceeding - accused's silence - nemo tenetur

* Licenciado en Ciencias Jurídicas y Sociales, Universidad de Chile. LL.M. Universidad Libre de Berlín, Alemania. Profesor de Derecho Procesal, Universidad Adolfo Ibáñez. Correo electrónico: c.correa@uai.cl

Agradezco especialmente a Jorge Cabrera Girao, y a los dos evaluadores anónimos por sus valiosos comentarios y correcciones.

Artículo recibido el 13 de diciembre de 2016 y aceptado para su publicación en este número el 23 de julio de 2018. 


\section{INTRODUCCIÓN}

C on la entrada en vigencia del Código Procesal Penal (CPP) hace más de 15 años, los tiempos en los que el imputado era considerado meramente un objeto del procedimiento y no un titular de derechos parecen haber quedado definitivamente atrás.

En concreto, la Reforma Procesal Penal supuso abandonar el sistema consagrado en el Código de Procedimiento Penal (CPP) de 1906, modelo de raigambre marcadamente inquisitiva, cuyo fin último era la búsqueda de la verdad material por parte del Juez del Crimen. Un mecanismo esencial para alcanzar el referido objetivo lo constituía la llamada declaración indagatoria, regulada detalladamente en los Arts. 318 ss. CPP. Mediante esta, el imputado era exhortado por el Juez (Art. 320 CPP) a que diga la verdad, advirtiéndole que debe responder de una manera clara y precisa a las preguntas que le dirigiere. La finalidad perseguida por medio de la declaración del imputado era la obtención de la tan anhelada confesión, medio de prueba regulado detalladamente en los Arts. 481 y ss. CPP. En cuanto regina probationum ${ }^{1}$ la confesión podía (bajo determinados supuestos) constituir plena prueba de la participación del imputado en el delito (Art. 481 CPP), liberando al sobrecargado Juez del Crimen de la necesidad de producir prueba adicional a este respecto.

Bajo la concepción original del CPP, el silencio del imputado no estaba reconocido como un derecho; por el contrario, este constituía un verdadero obstáculo para la investigación y consecuentemente para la búsqueda de la verdad material. Derivar consecuencias negativas de quien rehusaba declarar (y finalmente confesar) resultaba algo lógico y hasta esperable. En este sentido, el Art. 327 CPP asimilaba la situación del imputado que rebúsa contestar con aquel que se finge loco, sordo o mudo, indicándose que en ambos casos el juez limitará a hacer notar al inculpado que su actitud no impedirá la prosecución del proceso y que puede producir el resultado de privarle de algunos de sus medios de defensa.

La reforma al artículo 484 CPP por medio de la Ley Nº 18.857 de 1989 constituyó un punto de inflexión respecto del tratamiento jurídico conferido al silencio del imputado en el antiguo proceso penal. Con ella se incorporó un inciso segundo a la referida disposición, estableciendo a partir de entonces que el silencio del imputado no implicará un indicio de participación, culpabilidad o inocencia ${ }^{2}$. Al establecer el legislador chileno por vez primera una prohibición expresa de derivar consecuencias jurídicas del silencio ejercido por el imputado, aseguró y consagró -indirectamente- un derecho que (al menos a nivel legal) resultaba completamente desconocido.

Actualmente el CPP reconoce expresamente el derecho del imputado a guardar silencio (Art. 93 letra g) CPP). Como consecuencia de dicho reconocimiento, en la

${ }^{1}$ Vid. WilenmanN, "El tratamiento del autofavorecimiento del imputado. Sobre las consecuencias sustantivas del principio de no autoincriminación”, en RDUCN vol. 23 no.1. Coquimbo jun. 2016, pp. 116.

${ }^{2}$ El Art. 484 Inc. $2^{\circ} \mathrm{CPP}$ contiene la única referencia al silencio del acusado en todo el CPP. 
regulación actualmente vigente la declaración del imputado no responde al viejo paradigma inquisitivo de mecanismo para la averiguación de la verdad, sino que es entendida como un medio de defensa (Art. 98 CPP).

En contraposición al relativamente reciente reconocimiento legal del derecho a guardar silencio experimentado en Chile, en Alemania la consagración de dicho derecho ha debido recorrer un largo camino. En sus inicios, el sistema alemán no reconoció expresamente la existencia de un derecho a guardar silencio. A este respecto, el $\S 136$ de la Ordenanza Procesal Penal alemana (SPO) establecía en su redacción original de 1877 que el imputado, al momento de ser citado a prestar declaración, debía ser simplemente consultado por el funcionario a cargo si desea prestar declaración; la existencia de un derecho a guardar silencio no se encontraba consagrada expresamente a nivel legal. Dicha garantía fue recién incorporada casi 90 años después de la entrada en vigencia del referido cuerpo legal, mediante reforma introducida al mencionado $\$ 136$ en 1964 . Fue solo entonces cuando el legislador modificó la referida disposición pasando a su formulación actual, la que consagra el derecho del acusado a ser informado si desea libremente prestar declaración o guardar silencio ${ }^{3}$. Tras dicha reforma, la posibilidad reconocida al imputado de no prestar declaración en un proceso seguido en su contra se erige propiamente como un derecho establecido a su favor ${ }^{4}$.

Si bien en la actualidad tanto el CPP chileno como la SPO alemana reconocen el silencio del imputado en el proceso penal como un derecho, las consecuencias jurídicas que de su ejercicio se derivan siguen siendo -especialmente en lo referido a su incidencia acerca de la valoración de la prueba- objeto de discusión. Una definición al respecto resulta necesaria.

Punto de partida del presente estudio lo constituye la distinción efectuada por la doctrina y jurisprudencia mayoritaria en Alemania $^{5}$ entre el tratamiento del silencio total, temporal y parcial del imputado, categorías dogmáticas cuyo contenido y efectos jurídicos serán expuestos posteriormente y cuyo contenido resulta fundamental para sistematizar el tratamiento del tema en el derecho chileno.

En los siguientes capítulos se efectuará un análisis comparado a partir de la doctrina y la jurisprudencia alemana y chilena, referido a la valoración jurídica de las distintas manifestaciones que puede revestir el silencio del imputado en el proceso penal.

La importancia que reviste el análisis comparado de los temas objeto de la presente investigación, radica fundamentalmente en el escaso o nulo tratamiento que estos han recibido por parte de la doctrina y jurisprudencia chilena. En contraposición a ello, desde

${ }^{3}$ En lo relevante a la presente investigación, el $\$ 136$ SPO señala: Primer interrogatorio. Al comienzo del primer interrogatorio se le expondrán al imputado los hechos que se le imputan, así como las disposiciones legales pertinentes. Se le deberá advertir además, que de acuerdo a la ley es libre de declarar respecto de las imputaciones o bien, de guardar silencio así como del derecho aun antes de prestar declaración, de consultar al respecto a un abogado defensor (...) (las traducciones son nuestras).

${ }^{4}$ Vid. Wessels, J., “Schweigen und Leugnen im Strafverfahren”, en JuS 1966, p. 169.

${ }^{5}$ Por todos: Schneider, H., "Die strafprozessuale Beweiswürdigung des Schweigens von Beschuldigten und angehörigen Zeugen”, en JURA 1990, pp. 273 s. 
hace más de 50 años el derecho alemán ha discutido intensamente el tratamiento del silencio del imputado, generando un modelo diferenciado, cuya sistematización -hasta ahora ajena a nuestra tradición- puede enriquecer enormemente una discusión que en Chile, hasta ahora, ha resultado prácticamente estéril.

A este respecto, el artículo utilizará el llamado método de comparación funcionalista, el que examina distintos sistemas jurídicos a partir de problemas específicos que orientan el análisis ${ }^{6}$. Objeto central de este trabajo es precisamente evaluar críticamente las soluciones que la doctrina y jurisprudencia alemana ha dado a diversas problemáticas referidas al tratamiento del silencio del imputado en el proceso penal y -en caso de ser ello posible- utilizarlas como bases referenciales que permitan dar solución a interrogantes concretas referidas al sistema chileno.

\section{El Silencio TOTAL DEL imputado EN EL DERECHO ALEMÁN}

Si bien la mencionada reforma al $\$ 136$ SPO consagró legalmente el derecho del imputado a guardar silencio, el legislador no incluyó referencia alguna respecto de la forma en la que el juez debe tratar el silencio del acusado al momento de valorar la prueba $^{7}$. En efecto, del tenor literal actual de la referida disposición no resulta posible derivar automáticamente una prohibición de asignar al silencio un valor probatorio determinado, considerándolo por ejemplo como un indicio de responsabilidad ${ }^{8}$.

A falta de norma expresa, la pregunta acerca de la valoración jurídica del silencio del imputado es de naturaleza normativa. Ella busca en definitiva determinar la existencia o inexistencia de límites al principio de libre valoración de la prueba consagrado en el $\S 261$ SPO $^{9}$, que pudiesen impedir -o en su caso permitir-al juez derivar consecuencias concretas del uso del referido derecho ${ }^{10}$.

Buscando una respuesta a la pregunta formulada, se podría en primer término argumentar -desde un punto de vista meramente intuitivo- que el silencio ejercido por el imputado en el proceso penal sería el fiel reflejo de una responsabilidad penal que se intenta evadir. Concordante con dicho punto de vista argumentaba Kleinknecht ya en 1966 que el silencio del imputado constituye sin lugar a dudas una confirmación desde un punto de vista criminalístico, que la policía persigue a la persona correcta ${ }^{11}$. A partir de dicho

${ }^{6}$ Vid. Michaels, R. "The Functional Method of Comparative Law”, en Reimann/Zimmermann (coord.) The Oxford Handbook of Comparative Law, passim.

7 Stree, W., "Schweigen des Beschuldigten im Strafverfahren”, en JZ 1966, p. 593.

${ }^{8}$ Roxin, C./Schünemann, B., Strafverfahrensrecht: ein Studienbuch. 28. Ed., Beck. München, 2014, $\S 15, \operatorname{Rdn} .31$.

9 \$261 SPO: "Principio de libre valoración de la prueba. Sobre el resultado de la prueba rendida, decidirá el tribunal libremente de acuerdo al conjunto de prueba rendida en la audiencia”.

10 SK-SPO: Systematischer Kommentar zur Strafprozessordnung. Mit GVG und EMRK, Wolter (coord.). Tomo II: §§94-136a StPO, 5. Ed., Heymanns, Köln, 2016, Rogall §133, Rdn. 197.

${ }^{11}$ Kleinknecht, T., “Anmerkung zur Urteil des BGH 5. StS v. 26.10.65-5 StR 415/65”, en JR 1966 , p. 270. 
razonamiento, construir una máxima de la experiencia -basada en la constatación de un fenómeno general, subsumible por vía inductiva a un caso concreto ${ }^{12}$ - de la que resultaría posible desprender consecuencias negativas del silencio, resultaría para el citado autor algo completamente lógico.

Respecto de la posible valoración del silencio total del imputado (imputado que guarda silencio en todas y cada una de las etapas del procedimiento y respecto de todas las preguntas a él dirigidas), el antiguo Tribunal Supremo Imperial alemán (RG) ${ }^{13}$, si bien no resolvió directamente dicha pregunta, se inclinó en su jurisprudencia a favor de derivar conclusiones del silencio ejercido por testigos en uso de su derecho a no declarar en perjuicio de familiares. Dicha postura partía de una interpretación amplia del principio de libre valoración de la prueba, según esta, el juez no se encontraría sujeto a límite alguno al momento de apreciarla.

De este modo, al no existir regla expresa que establezca anticipadamente el valor que debe conferírsele a la prueba rendida, ni principio alguno que prohíba al juez dar valor probatorio al silencio ejercido por el acusado, aceptar la posibilidad de valorar el silencio resultaba una consecuencia lógica e incluso esperable.

En concordancia con dicha línea argumentativa, advertía Günther ${ }^{14}$ la existencia de una contradicción en caso de aceptar por un lado la valoración de la declaración efectivamente prestada por el imputado (aun contra su voluntad), pero impedir por otro derivar consecuencias jurídicas de su silencio. Dicha inconsistencia, sostiene el autor mencionado, sería atentatoria contra el sistema de libre valoración de la prueba $^{15}$.

${ }^{12}$ Lo anterior de acuerdo con la formulación de máximas de la experiencia (Erfabrunssätze) originalmente planteada por Stein, F., Das Private Wissen des Richters, pp. 16 y ss. En el derecho chileno vid. Correa, C. "Comentario Sentencia Ingreso N 18-2013, Corte de Apelaciones de Valparaíso, Infracción a las reglas reguladoras de la prueba”, en Revista Chilena de Derecho y Ciencias Penales, 2013, p. 186; PAILlás, E., Estudios

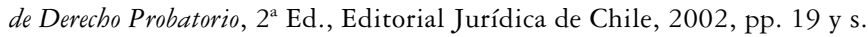

${ }^{13}$ RGSt 55, 20; RG HRR 1939, 729. En este sentido también BGHSt 2, 351 (353 s.).

${ }^{14}$ GüNther, H., "Strafrechtliche Beweiswürdigung und schweigender Angeklagter", en JR 1978, pp. 90 ss.

${ }^{15}$ Es factible señalar que para Günther el hecho de incluir al silencio dentro de la libre valoración de la prueba no implicaba directamente deducir de este consecuencias negativas para el imputado. El silencio solo podría ser valorado en contra del acusado cuando el juez considere que su origen se encuentra en la imposibilidad del imputado de proporcionar antecedentes que permitan desacreditar su participación criminal. GüNther, H., "Strafrechtliche Beweiswürdigung und schweigender Angeklagter”, en JR 1978, pp. 90 ss. 
Actualmente, la doctrina ampliamente mayoritaria ${ }^{16}$ y la jurisprudencia del Tribunal Supremo Federal $(\mathrm{BGH})^{17}$ (sucesor del antiguo RG), del Tribunal Constitucional $(\mathrm{BVerfG})^{18}$ y de los Tribunales Superiores Estatales (OLG) ${ }^{19}$ sostiene acertadamente que el silencio total del acusado -independiente de las razones que lo motivan ${ }^{20}$ - se encuentra completamente excluido del ámbito de aplicación de la libre valoración de la prueba, no pudiendo ser apreciado de manera alguna por parte del juez.

Dicha prohibición de valoración rige respecto del silencio prestado por el imputado en cualquier etapa del procedimiento ${ }^{21}$, y no solamente ante el juez, sino también frente el fiscal o la policía ${ }^{22}$. Igualmente, si una persona es imputada por distintos delitos,

${ }^{16}$ Entre otros: Beulke, W., Strafprozessrecht. 12. Ed., Müller, Heidelberg y otros, 2012, Rdn. 495; Dahs, H./Langkeit, J., "Das Schweigerecht des Beschuldigten und seine Auskunftsverweigerung als "verdächtiger Zeuge”, en NStZ 1993, p. 214; EISENBErg, U., Beweisrecht der StPO: Spezialkommentar, 9. Ed., Beck, München, 2015, Rdn. 899; FEzER, G., Strafprozeßrecht. 2. Ed., Beck, München, 1995, p. 233; LöwERosenberG: "Die Strafprozeßordnung und das Gerichtsverfassungsgesetz. Großkommentar", Becker/Erb/ Esser/Graalmann-Scheerer/Hilger/Ignor (coord.), de Gruyter, Berlin y otros, IV Tomo: $\$ 112-150,26$. Ed., 2007, Gleß §136, Rdn. 36; Grünwald, G., Das Beweisrecht der Strafprozeßordnung, Nomos, Baden-Baden, 1993, p. 66; Hammerstein, G., "Sachaufklärung durch inquisitorische Vernehmung des Angeklagten", en: Kürzinger, J./Müller, E. (coord.), Festschrift für Wolf Middendorff zum 70. Geburtstag, Bielefeld, 1986, p. 114; JäGER, C., “Anmerkung zum Urteil des BGH v. 18.04.2002-3 StR 370/01”, en JR 2003, p. 167; KüHL, K., "Freie Beweiswürdigung des Schweigens des Angeklagten und der Untersuchungsweigerung eines angehörigen Zeugen - BGHSt 32, 140", en JuS 1986, p. 118; Miebach, K., "Der teilschweige Angeklagte - materiell-rechtliche und prozessuale Fragen anhand der BGH-Rechtsprechung", en NStZ 2000, p. 235; Müller-Christmann, B., “Aktuelles Strafprozessrecht”, en JuS 2001, p. 61; Park, T., "Die prozessuale Verwertbarkeit verschiedener Formen der Beschuldigteneinlassung im Strafverfahren”, en $S t V$ 2001, p. 589; Pelchen, G., “Anmerkung zum Urteil des BGH v. 26.10.1983-3 StR 251/83 (BGHSt. 32, 140)”, en JR 1985, p. 74; SK-StPO: Systematischer Kommentar zur Strafprozessordnung. Mit GVG und EMRK, Wolter (coord.). Tomo II: \$\$94-136a StPO, 5. Ed., Heymanns, Köln, 2016, Rogall §133, Rdn. 198; Rogall, K., Der Beschuldigte als Beweismittel gegen sich selbst: ein Beitrag zur Geltung des Satzes "Nemo tenetur seipsum prodere" im Strafprozeß. Duncker \& Humblot, Berlin, 1977, pp. 247 ss.; 277 ss; RogaLl, K., “Anmerkung zum Urteil des BGH v. 26.3.1992-5 StR 122/92 (BGHSt 38, 302)”, en JR 1993, p. 381; Roxin, C./Schünemann, B., Strafverfahrensrecht: ein Studienbuch. 28. Ed., Beck. München, 2014, \$25, Rdn. 31; RüpING, H., "Zur Mitwirkungspflicht des Beschuldigten und Angeklagten”, en JR 1974, p. 138; Schlüchter, E., Das Strafverfahren. 2. Ed., Heymanns, Köln y otros, 1983, Rdn. 467; Schneider, H., "Die strafprozessuale Beweiswürdigung des Schweigens von Beschuldigten und angehörigen Zeugen”, en JURA 1990, p. 576; STREe, W., "Schweigen des Beschuldigten im Strafverfahren”, en JZ 1966, pp. 594 ss.

17 BGHSt 22, 113; 25, 365 (368); 32, 140 (144); 38, 302 (305); BGH NJW 2000, 1426; BGH NStZ 2000, 495.

${ }^{18}$ BVerfG NStZ 1995, 555; BVerfGE 56, 37 (51)

${ }^{19}$ OLG Karlsruhe StraFo 2004, 355; OLG Düsseldorf MDR 1988, 796; OLG Stuttgart NStZ 1986, 182; OLG Stuttgart NStZ 1981, 272; OLG Hamm NJW 1974, 1880 s.; OLG Hamm NJW 1973, 1708; OLG Oldenburg NJW 1969, 806.

${ }^{20} \mathrm{MiebaCH}, \mathrm{K}$., "Der teilschweige Angeklagte - materiell-rechtliche und prozessuale Fragen anhand der BGH-Rechtsprechung”, en NStZ 2000, p. 235.

${ }^{21}$ Eisenberg, U., Beweisrecht der StPO: Spezialkommentar, 9. Ed., Beck, München, 2015, Rdn. 899a; BVerfG NStZ 95, 555 .

${ }^{22}$ BGHSt 20, 281 (282 s.); BGH StraFo 96, 121. 
y decide declarar respecto de algunos guardando sin embargo silencio respecto de preguntas referidas a otras imputaciones, su silencio no podrá ser interpretado en su perjuicio ${ }^{23}$.

La fundamentación estándar esgrimida por la jurisprudencia ${ }^{24}$ para llegar a dicha conclusión consiste en entender el derecho a guardar silencio como una manifestación concreta de la garantía de no autoincriminación - nemo tenetur se ipsum accusare ${ }^{25}$ - contenida en los $\$ \$ 136$ inc. $1^{\circ}, 163$ letra a) inc. $3^{\circ}, 243$ inc. $5^{\circ}$ de la SPO, y en el art. 14 Inc. $3^{\circ}$ letra g) del Pacto Internacional de Derechos Civiles y Políticos. Dicha garantía asegura al imputado la posibilidad de decidir, libre de toda presión, si y en qué medida desea intervenir en el proceso penal. En este sentido, el nemo tenetur protege al acusado de ser obligado a prestar declaración y de esta forma de contribuir activamente a la formación de convicción en su contra ${ }^{26}$. El derecho de no autoincriminación corresponde en este sentido - de acuerdo al BVerfG- a una garantía de rango constitucional y esencial de un Estado de Derecho, fundada en el respeto por la dignidad humana ${ }^{27}$. Su resguardo, manifestado paradigmáticamente en la imposibilidad de valorar el silencio, corresponde a un deber inexcusable por parte del Estado ${ }^{28}$.

${ }^{23}$ Beulke, W., Strafprozessrecht. 12. Ed., Müller, Heidelberg y otros, 2012, Rdn. 495; Eisenberg, U., Beweisrecht der StPO: Spezialkommentar, 9. Ed., Beck, München, 2015, Rdn. 907a; Löwe-Rosenberg: Die Strafprozeßordnung und das Gerichtsverfassungsgesetz. Großkommentar, Becker/Erb/Esser/GraalmannScheerer/Hilger/Ignor (coord.), de Gruyter, Berlin y otros, IV Tomo: $\$ 112-150,26$. Ed., 2007, Gleß $\$ 136$ Rdn. 38; JäGER, C., “Anmerkung zum Urteil des BGH v. 18.04.2002-3 StR 370/01”, en JR 2003, p. 167; KüHL, K., "Freie Beweiswürdigung des Schweigens des Angeklagten und der Untersuchungsweigerung eines angehörigen Zeugen - BGHSt 32, 140”, en JuS 1986, p. 119; PELCHEN, G., "Anmerkung zum Urteil des BGH v. 26.10.1983-3 StR 251/83 (BGHSt. 32, 140)”, en JR 1985, p. 74; SK-StPO: Systematischer Kommentar zur Strafprozessordnung. Mit GVG und EMRK, Wolter (coord.). Tomo II: §§94-136a StPO, 5. Ed., Heymanns, Köln, 2016, Rogall \$133 Rdn. 200; SCHNeider, H., "Die strafprozessuale Beweiswürdigung des Schweigens von Beschuldigten und angehörigen Zeugen”, en JURA 1990, p. 580; VolK, K., “Anmerkung zum Urteil des BGH v. 26.10.1983-3 StR 251/83 (LG Duisburg)”, en NStZ 1984, p. 378. En la jurisprudencia: BGHSt 32, 140 (145); BGH NStZ 2000, 494; OLG Karlsruhe StraFo 2004, 355.

${ }^{24}$ BGHSt 25, 325 (330); 38, 214 (220 s.); 38, 302 (305); BGH NJW 1974, 1570; BGH NStZ 2000, 495; OLG Stuttgart NStZ 1986, 182; BVerfG NStZ 95, 555.

25 Acerca de la evolución histórica del principio de no autoincriminación vid. WILENMANN, "El tratamiento del autofavorecimiento del imputado. Sobre las consecuencias sustantivas del principio de no autoincriminación”, en RDUCN vol. 23 no.1 Coquimbo jun. 2016, pp. 115 y ss.

${ }^{26}$ En este sentido: Eisenberg, U., Beweisrecht der StPO: Spezialkommentar, 9. Ed., Beck, München, 2015, Rdn. 899; Kasiske, P., "Die Selbstbelastungsfreiheit im Strafprozess”, en JuS 2014, p. 17; PARK, T., "Die prozessuale Verwertbarkeit verschiedener Formen der Beschuldigteneinlassung im Strafverfahren”, en $S t V$ 2001, p. 589; Rogall, K., Der Beschuldigte als Beweismittel gegen sich selbst: ein Beitrag zur Geltung des Satzes "Nemo tenetur seipsum prodere" im Strafprozeß. Duncker \& Humblot, Berlin, 1977, p. 249; Stree, W., "Schweigen des Beschuldigten im Strafverfahren", en JZ 1966, pp. 595 s.

27 BVerfGE 133, 168 (201); 110, 1 (31); 56, 37 (43); 55, 144 (150 s.); 38, 105 (113 s.). Al respecto pormenorizadamente: Ransiek, A./Winsel, A., "Die Selbstbelastung im Sinne des "nemo tenetur se ipsum accusare"-Grundsatzes", en GA 2015, pp. 620 ss.

${ }^{28}$ BVerfGE 38, 105 (113); 56, 37 (43); BVerfG NStZ 95, 555. 
Como segundo fundamento de la prohibición de valoración, sostiene la doctrina mayoritaria ${ }^{29}$ que aceptar la valoración del silencio generaría en el inculpado una verdadera obligación de declarar. Así, ante la amenaza de una interpretación del silencio contraria a sus intereses, la decisión del imputado de guardar o no silencio carecería por completo de libertad; el ejercicio de un derecho constituiría más bien una potencial fuente de perjuicios para su titular, deviniendo este en un verdadero privilegium odiosum ${ }^{30}$ : la vigencia del derecho a no autoincriminarse sería entonces meramente ilusoria ${ }^{31}$. En síntesis, la libertad de declarar solo puede entenderse garantizada si el imputado no teme que su ejercicio le ocasionará un perjuicio; solo así podrá decidir entre ambas alternativas $^{32}$.

De esta forma, como acertadamente ha sostenido Rogall ${ }^{33}$, el sistema de libre valoración de la prueba resultará compatible con el respeto a las garantías del imputado en el proceso penal, solo si se reconoce como un límite a este el derecho de cada individuo a no contribuir activamente al establecimiento de su responsabilidad penal, manifestado en el derecho a guardar silencio.

Dicho lo anterior, es posible concluir que la pretensión formulada por Günther, en orden a equiparar los efectos jurídicos de la declaración y del silencio, resulta incompatible con un efectivo resguardo del derecho referido. En efecto, el imputado que voluntariamente decide declarar lo hace a sabiendas que su declaración será valorada

29 Fezer, G., Strafprozeßrecht. 2. Ed., Beck, München, 1995, p. 233; Löwe-Rosenberg: Die Strafprozeßordnung und das Gerichtsverfassungsgesetz. Großkommentar, Becker/Erb/Esser/Graalmann-Scheerer/ Hilger/Ignor (coord.), de Gruyter, Berlin y otros, IV Tomo: §§112-150, 26. Ed., 2007, Gleß §136 Rdn. 36; KüHL, K., "Freie Beweiswürdigung des Schweigens des Angeklagten und der Untersuchungsweigerung eines angehörigen Zeugen-BGHSt 32, 140", en JuS 1986, p. 118; PARK, T., "Die prozessuale Verwertbarkeit verschiedener Formen der Beschuldigteneinlassung im Strafverfahren”, en StV 2001, p. 589; RogaLl, K., Der Beschuldigte als Beweismittel gegen sich selbst: ein Beitrag zur Geltung des Satzes "Nemo tenetur seipsum prodere” im Strafprozeß. Duncker \& Humblot, Berlin, 1977, p. 249; SCHNEIDER, H., "Die strafprozessuale Beweiswürdigung des Schweigens von Beschuldigten und angehörigen Zeugen”, en JURA 1990, p. 577; Wessels, J., "Schweigen und Leugnen im Strafverfahren", en JuS 1966, p. 171. Contra: GüNTHER, H., "Strafrechtliche Beweiswürdigung und schweigender Angeklagter", en JR 1978, pp. 91 s.

${ }^{30}$ Cfr. Aselmann, M., “Anmerkung zum Beschluß des BGH v. 3.5.2000-1 StR 125/00”, en JR 2001, p. 81; Wessels, J., “Schweigen und Leugnen im Strafverfahren”, en JuS 1966, p. 171.

31 Aselmann, M., “Anmerkung zum Beschluß des BGH v. 3.5.2000-1 StR 125/00”, en JR 2001, p. 81; JäGER, C., “Anmerkung zum Urteil des BGH v. 18.04.2002-3 StR 370/01”, en JR 2003, p. 167; SK-StPO: Systematischer Kommentar zur Strafprozessordnung. Mit GVG und EMRK, Wolter (coord.). Tomo II: §§94-136a StPO, 5. Ed., Heymanns, Köln, 2016, Rogall §133, Rdn. 197 s; Rogall, K., Der Beschuldigte als Beweismittel gegen sich selbst: ein Beitrag zur Geltung des Satzes "Nemo tenetur seipsum prodere” im Strafprozeß. Duncker \& Humblot, Berlin, 1977, p. 249. BVerfG NStZ 95, 555; OLG Düsseldorf StV 1983, 450.

${ }^{32}$ KüHL, K., "Freie Beweiswürdigung des Schweigens des Angeklagten und der Untersuchungsweigerung eines angehörigen Zeugen-BGHSt 32, 140”, en JuS 1986, pp. 118 s; SK-StPO: Systematischer Kommentar zur Strafprozessordnung. Mit GVG und EMRK, Wolter (coord.). Tomo II: §§94-136a StPO, 5. Ed., Heymanns, Köln, 2016, Rogall §133, Rdn. 199; STREE, W., "Schweigen des Beschuldigten im Strafverfahren", en JZ 1966 , p. 595.

${ }^{33}$ Rogall, K., Der Beschuldigte als Beweismittel gegen sich selbst: ein Beitrag zur Geltung des Satzes "Nemo tenetur seipsum prodere” im Strafprozeß. Duncker \& Humblot, Berlin, 1977, p. 249. 
por el juez. Por el contrario, quien decide callar lo hace precisamente a efectos de no ser considerado -en modo alguno- medio de prueba por parte del tribunal ${ }^{34}$.

El tercer fundamento esgrimido por parte de la doctrina alemana para rechazar la valoración jurídica del silencio total del imputado radica en la imposibilidad práctica de determinar su valor probatorio. En efecto, la existencia de motivos tan diversos para guardar silencio ${ }^{35}$ como el miedo, la intimidación ante una persecución penal, el olvido, la vergüenza, ciertas consecuencias sociales indeseadas, la inseguridad, el riesgo de confusión ante un eventual contrainterrogatorio, o simplemente el temor de confesar un delito, no pueden ser reconducidos indistintamente a un indicio de contenido idéntico. Ante la imposibilidad de constatar por medio del silencio un fenómeno unívoco susceptible de ser subsumido en una regla jurídica, la existencia de una máxima de la experiencia, según esta, un acusado solo calla cuando es culpable, deberá ser desestimada ${ }^{36}$.

Para asignar un valor probatorio específico al silencio alejado de la mera especulación, resultaría necesario efectuar un examen de los motivos que el imputado tuvo en consideración al momento de optar por no declarar ${ }^{37}$. Aunque teóricamente factible determinar caso a caso el valor probatorio del silencio a base de sus distintas motivaciones, escapa de las facultades del juez. En efecto, las razones que inducen a un imputado a no declarar corresponden a estímulos internos infranqueables, una verdadera "caja negra" 38 ajena a la percepción sensorial de terceros. Su averiguación directa por medio de un interrogatorio se encuentra -como corolario del reconocimiento de un derecho a no autoincriminación- del todo vedada para el juez y los intervinientes ${ }^{39}$.

Respecto del contenido mismo del silencio, la jurisprudencia del Tribunal Supremo alemán ${ }^{40}$ ha señalado que el silencio total del imputado no debe entenderse como una

${ }^{34}$ SK-StPO: Systematischer Kommentar zur Strafprozessordnung. Mit GVG und EMRK, Wolter (coord.). Tomo II: §§94-136a StPO, 5. Ed., Heymanns, Köln, 2016, Rogall \$133, Rdn. 199.

35 Un catálogo extenso de motivos que pueden llevar al imputado a guardar silencio se encuentra en: Aselmann, M., “Anmerkung zum Beschluß des BGH v. 3.5.2000-1 StR 125/00”, en JR 2001, p. 81.

${ }^{36}$ ders., JR 2001, 80 (81); Löwe-Rosenberg: Die Strafprozeßordnung und das Gerichtsverfassungsgesetz. Großkommentar, Becker/Erb/Esser/Graalmann-Scheerer/Hilger/Ignor (coord.), de Gruyter, Berlin y otros, IV Tomo: $§ \S 112-150,26$. Ed., 2007, Gle $\beta \$ 136$ Rdn. 36; KüHL, K., "Freie Beweiswürdigung des Schweigens des Angeklagten und der Untersuchungsweigerung eines angehörigen Zeugen-BGHSt 32, 140", en JuS 1986, p. 119; Meyer, K., “Anmerkung zum Urteil des BGH 4. StS v. 3.12.65-4 StR 573/65”, en JR 1966, p. 352; SснміDт, E., “\$261 StPO in der neueren höchstrichterlichen Rechtsprechung”, en JZ 1970, p. 341; SchNeIDER, H., "Die strafprozessuale Beweiswürdigung des Schweigens von Beschuldigten und angehörigen Zeugen”, en JURA 1990, p. 577.

${ }^{37}$ KüHL, K., "Freie Beweiswürdigung des Schweigens des Angeklagten und der Untersuchungsweigerung eines angehörigen Zeugen-BGHSt 32, 140”, en JuS 1986, p. 119.

${ }^{38}$ La expresión corresponde a Aselmann, M., "Anmerkung zum Beschluß des BGH v. 3.5.2000-1 StR 125/00”, en JR 2001, p. 81.

${ }^{39}$ Cfr. Günther, H., "Strafrechtliche Beweiswürdigung und schweigender Angeklagter", en JR 1978, p. 94; KüHL, K., "Freie Beweiswürdigung des Schweigens des Angeklagten und der Untersuchungsweigerung eines angehörigen Zeugen-BGHSt 32, 140", en JuS 1986, p. 119; SCHNEIDER, H., "Die strafprozessuale Beweiswürdigung des Schweigens von Beschuldigten und angehörigen Zeugen”, en JURA 1990, p. 577; Wessels, J., "Schweigen und Leugnen im Strafverfahren”, en JuS 1966, p. 172.

${ }^{40}$ BGH NStZ 97, 147; BGHSt 32, 140 (145). 
absoluta omisión de emitir cualquier declaración en un proceso penal, sino más bien como una negativa del imputado a dar respuesta total o parcial a imputaciones concretas dirigidas en su contra. Así por ejemplo, los gestos expresados por el acusado durante el juicio oral, la escueta referencia efectuada por el imputado en orden a "no haber cometido el hecho", sin proporcionar mayor información al respecto, o bien la mención por parte del imputado de estar "consciente de su deber de declarar algo respecto de los hechos que se le imputan", han sido considerados como verdaderos equivalentes funcionales del silencio total ${ }^{41}$, a cuyo respecto se extiende la imposibilidad por parte del juez de derivar consecuencias negativas para el imputado.

Sin perjuicio de lo señalado, es posible tener presente desde un punto de vista estratégico, que el ejercicio por parte del imputado de su derecho a guardar silencio puede en ciertos casos ser perjudicial para su defensa ${ }^{42}$. Si bien el silencio no puede ser objeto de valoración alguna, ello desde luego no obsta a que el tribunal pueda formar su convicción a partir de otros medios de prueba. Igualmente, el ejercicio del derecho a guardar silencio importa una renuncia a un medio de defensa, restringiendo con ello las posibilidades de controvertir la veracidad de las imputaciones formuladas y el valor de ciertos elementos probatorios presentados en juicio. Finalmente, el silencio muchas veces privará al imputado de la posibilidad de exponer circunstancias exculpatorias que por otros medios jamás llegarán a oídos del juez ${ }^{43}$.

\section{SilENCIO TEMPORAL DEL IMPUTADO EN EL DERECHO ALEMÁN}

El silencio temporal tiene lugar en aquellos casos en los que el imputado es citado a prestar declaración en distintas etapas del procedimiento, optando por declarar en algunas, guardando silencio en otras, o bien cuando ante reiteradas citaciones en una misma etapa del procedimiento, decide declarar en una(s) y callar en otra(s).

El silencio temporal del imputado -sostiene la doctrina y la jurisprudencia alemana ${ }^{44}$ - tampoco puede ser objeto de valoración por parte del juez.

${ }^{41}$ BGHSt 25, 365 (368); 34, 325 (326); 38, 302 (307); BGH NStZ 2007, 419; BGH NStZ 2000, 495; OLG Karlsruhe StraFo 2004, 355; OLG Düsseldorf MDR 1988, 796 s.; OLG Hamm NJW $1973,1708$.

${ }^{42}$ Cfr. Hammerstein, G., "Sachaufklärung durch inquisitorische Vernehmung des Angeklagten", en: KürZinger, J./Müller, E. (coord.), Festschrift für Wolf Middendorff zum 70. Geburtstag, Bielefeld, 1986, p. 114; KüHL, K., "Freie Beweiswürdigung des Schweigens des Angeklagten und der Untersuchungsweigerung eines angehörigen Zeugen-BGHSt 32, 140", en JuS 1986, p. 118; STREE, W., "Schweigen des Beschuldigten im Strafverfahren", en JZ 1966, p. 596; Wessels, J., "Schweigen und Leugnen im Strafverfahren”, en JuS 1966, pp. 172 s. En el derecho chileno vid. Ramirez Tagle, C. "Nemo Tenetur Se Ipsum. El Derecho a guardar silencio", en Ars Boni et Aequi, 2007, pp. 75 ss.

43 Hammerstein, G., "Sachaufklärung durch inquisitorische Vernehmung des Angeklagten”, en: KürZinger, J./Müller, E. (coord.), Festschrift für Wolf Middendorff zum 70. Geburtstag, Bielefeld, 1986, p. 114.

${ }^{44}$ Beulke, W., Strafprozessrecht. 12. Ed., Müller, Heidelberg y otros, 2012, Rdn. 495; EISENBERG, U., Beweisrecht der StPO: Spezialkommentar, 9. Ed., Beck, München, 2015, Rdn. 902; Löwe-Rosenberg: Die Strafprozeßordnung und das Gerichtsverfassungsgesetz. Großkommentar, Becker/Erb/Esser/GraalmannScheerer/Hilger/Ignor (coord.), de Gruyter, Berlin y otros, IV Tomo: §§112-150, 26. Ed., 2007, Gle $\beta$ \$136 
Lo anterior rige independiente del momento en el que el titular del derecho decide guardar silencio. Así, cuando el imputado durante la fase de investigación ha prestado declaración (por ejemplo, ante la policía) y posteriormente, en la audiencia de juicio decide callar, su silencio se encuentra excluido de la valoración del tribunal ${ }^{45}$. Lo mismo sucede en el caso contrario, esto es respecto del imputado que guarda silencio durante la fase de investigación, declarando sin embargo en el juicio ${ }^{46}$.

Un componente esencial del derecho a guardar silencio corresponde a la libertad de ejercerlo en cualquier instancia del procedimiento ${ }^{47}$. De esta forma, permitir la valoración del silencio ejercido por el imputado en un momento determinado conllevaría una inaceptable restricción del alcance del derecho. En efecto, si el imputado -por ejemplo-considera guardar silencio durante la etapa de investigación, pero sabe que en caso de declarar posteriormente en el juicio oral su silencio previo podría ser valorado

Rdn. 37; JäGER, C., “Anmerkung zum Urteil des BGH v. 18.04.2002-3 StR 370/01”, en JR 2003, p. 167; KüHL, K., "Freie Beweiswürdigung des Schweigens des Angeklagten und der Untersuchungsweigerung eines angehörigen Zeugen-BGHSt 32, 140", en JuS 1986, p. 120; МıвасH, K., "Der teilschweige Angeklagte - materiell-rechtliche und prozessuale Fragen anhand der BGH-Rechtsprechung”, en NStZ 2000, pp. 239 s.; Ostermeyer, H., "Der schweigende Beschuldigte", en NJW 1967, p. 916; Park, T., "Die prozessuale Verwertbarkeit verschiedener Formen der Beschuldigteneinlassung im Strafverfahren”, en StV 2001, p. 590; Pelchen, G., “Anmerkung zum Urteil des BGH v. 26.10.1983-3 StR 251/83 (BGHSt. 32, 140)”, en JR 1985, p. 74; SK-StPO: Systematischer Kommentar zur Strafprozessordnung. Mit GVG und EMRK, Wolter (coord.). Tomo II: §§94-136a StPO, 5. Ed., Heymanns, Köln, 2016, Rogall §133, Rdn. 203; RoGALl, K., Der Beschuldigte als Beweismittel gegen sich selbst: ein Beitrag zur Geltung des Satzes "Nemo tenetur seipsum prodere” im Strafprozeß. Duncker \& Humblot, Berlin, 1977, p. 250; SCHLÜCHTER, E., Das Strafverfahren. 2. Ed., Heymanns, Köln y otros, 1983, Rdn. 467; SCHNEIDER, H., "Die strafprozessuale Beweiswürdigung des Schweigens von Beschuldigten und angehörigen Zeugen”, en JURA 1990, p. 578; Wessels, J., "Schweigen und Leugnen im Strafverfahren”, en JuS 1966, p. 172. En la jurisprudencia: BGH NStZ 2014, 667; BGHSt 20, 281; 25, 365 (368); 38, 302 (305); BGH NStZ 1999, 47; BGH NStZ-RR 2005, 147 s.; BGH StraFo 02, 14; OLG Köln NStZ 91, 52; OLG Stuttgart NStZ 86, 182; OLG Stuttgart NStZ 81, 272; OLG Hamm NJW 1974, 1881. Contra: OLG Oldenburg NJW 1969, 806; KLEINKNECHT, T., "Anmerkung zur Urteil des BGH 5. StS v. 26.10.65-5 StR 415/65“ en JR 1966, p. 270, quien sostiene que el silencio temporal del imputado debe ser objeto de valoración por parte del tribunal.

45 Eisenberg, U., Beweisrecht der StPO: Spezialkommentar, 9. Ed., Beck, München, 2015, Rdn. 903; Miebach, K., "Der teilschweige Angeklagte - materiell-rechtliche und prozessuale Fragen anhand der BGH-Rechtsprechung”, en NStZ 2000, p. 239; Rogall, K., Der Beschuldigte als Beweismittel gegen sich selbst: ein Beitrag zur Geltung des Satzes "Nemo tenetur seipsum prodere” im Strafprozeß. Duncker \& Humblot, Berlin, 1977, p. 250. En la jurisprudencia: BGHSt 32, 140 (145); BGH StV 84, 143; 88, 239; OLG Köln NStZ 1991, 52; OLG Stuttgart NStZ 1986, 182; OLG Zweibrücken StV 86, 290.

${ }^{46}$ Miebach, K., "Der teilschweige Angeklagte - materiell-rechtliche und prozessuale Fragen anhand der BGH-Rechtsprechung”, en NStZ 2000, p. 239. En la jurisprudencia: BGH NStZ 2014, 667; BGH MDR 1992, 323; BGHSt 20, 281 (282 s.); 38, 302 (305); OLG Köln NStZ 91, 52.

${ }^{47}$ KüHL, K., "Freie Beweiswürdigung des Schweigens des Angeklagten und der Untersuchungsweigerung eines angehörigen Zeugen - BGHSt 32, 140", en JuS 1986, p. 120; SK-StPO: Systematischer Kommentar zur Strafprozessordnung. Mit GVG und EMRK, Wolter (coord.). Tomo II: §§94-136a StPO, 5. Ed., Heymanns, Köln, 2016, Rogall \$133, Rdn. 203; SchneIder, H., "Die strafprozessuale Beweiswürdigung des Schweigens von Beschuldigten und angehörigen Zeugen”, en JURA 1990, p. 578. 
en su perjuicio, la libertad de declarar o callar, y finalmente la vigencia de su derecho a guardar silencio quedaría en entredicho ${ }^{48}$.

Sin perjuicio de lo anterior, el derecho a guardar silencio no impide traer a colación -por otros medios de prueba-declaraciones previamente prestadas ${ }^{49}$. En efecto, la declaración de un imputado que durante la fase de investigación prestó declaración pero que posteriormente decidió guardar silencio, puede -sostiene la doctrina mayoritaria_-50 ser válidamente introducida al juicio oral, por ejemplo, por medio del testimonio de los funcionarios que estuvieron presentes al momento en que tuvo lugar la declaración.

\section{Silencio PARCiAl Del imputado EN EL DERECHO ALEMÁN}

Del silencio total y temporal del acusado, se distingue el silencio parcial. Dicho concepto enmarca a aquel imputado que si bien decide declarar (en cualquier etapa del procedimiento) lo hace limitando su declaración exclusivamente respecto de algunos puntos o preguntas específicas, guardando silencio ${ }^{51}$ o bien dando respuestas vagas ${ }^{52}$ a preguntas concretas destinadas a acreditar la realización del delito y su participación en el mismo.

En Alemania, tanto la jurisprudencia ${ }^{53}$ como la doctrina mayoritaria ${ }^{54}$ han entendido que el silencio parcial resulta susceptible de ser valorado por parte del tribunal,

\footnotetext{
${ }^{48}$ BGHSt 38, 302 (305).

${ }^{49}$ BGH NJW 66, 1524.

${ }^{50}$ Eisenberg, U., Beweisrecht der StPO: Spezialkommentar, 9. Ed., Beck, München, 2015, Rdn. 905;
} KüHL, K., "Freie Beweiswürdigung des Schweigens des Angeklagten und der Untersuchungsweigerung eines angehörigen Zeugen - BGHSt 32, 140”, en JuS 1986, p. 120; MiEbaCH, K., “Der teilschweige Angeklagte - materiell-rechtliche und prozessuale Fragen anhand der BGH-Rechtsprechung”, en NStZ 2000, p. 240; PARK, T., "Die prozessuale Verwertbarkeit verschiedener Formen der Beschuldigteneinlassung im Strafverfahren”, en StV 2001, p. 590; STREe, W., "Schweigen des Beschuldigten im Strafverfahren”, en $J Z$ 1966, p. 596. En la jurisprudencia: BGH NStZ 1999, 47.

${ }^{51}$ BGH NStZ-RR 05, 148.

52 OLG Celle NJW 74, 202.

${ }^{53}$ BGH NStZ-RR 2005, 147 s.; BGH JR 2003, 165 s.; BGH NStZ 2000, 495; BGH NStZ 1999, 47; BGHSt 45, 367 (369); 32, 140 (145); 20, 298 (300); OLG Zweibrücken StV 1986, 290; OLG Oldenburg NJW 1969, 806 s.; OLG Hamm NJW 1974, 1881; OLG Hamm NJW 1973, 1708.

${ }^{54}$ Beulke, W., Strafprozessrecht. 12. Ed., Müller, Heidelberg y otros, 2012, Rdn. 495; DAHs, H./ LANGKeit, J., "Das Schweigerecht des Beschuldigten und seine Auskunftsverweigerung als "verdächtiger Zeuge”, en NStZ 1993, p. 214; Löwe-Rosenberg: Die Strafprozeßordnung und das Gerichtsverfassungsgesetz. Großkommentar, Becker/Erb/Esser/Graalmann-Scheerer/Hilger/Ignor (coord.), de Gruyter, Berlin y otros, IV Tomo: $\$ 112-150,26$. Ed., 2007, Gleß $\$ 136$ Rdn. 38; GrüNwald, G., Das Beweisrecht der Strafprozeßordnung, Nomos, Baden-Baden, 1993, p. 66; KLEINKNECHT, T., "Anmerkung zur Urteil des BGH 5. StS v. 26.10.65-5 StR 415/65“ en JR 1966, p. 270; Meyer, K., “Anmerkung zum Urteil des BGH 4. StS v. 3.12.65-4 StR 573/65”, en JR 1966, p. 352; Meyer-Gossner, L./SChMitT, B., Strafprozessordnung: Gerichtsverfassungsgesetz, Nebengesetze und ergänzende Bestimmungen. 58. Ed., Beck, München, 2015, §261, Rdn. 17; Müller-Christmann, B., “Aktuelles Strafprozessrecht”, en JuS 2001, p. 61; Pelchen, G., “Anmerkung zum Urteil des BGH v. 26.10.1983-3 StR 251/83 (BGHSt. 32, 140)”, en JR 1985, p. 74; Roxin, C., C./Schünemann, B., Strafverfahrensrecht: ein Studienbuch. 28. Ed., Beck. München, 2014, 
considerándose como un indicio en contra del imputado. Dicha valoración del silencio parcial ha sido justificada recurriendo a diversos argumentos.

En primer término, se ha sostenido ${ }^{55}$ que al momento de comenzar a declarar el imputado renunciaría completamente a su derecho a guardar silencio, transformándose -por medio de su declaración parcial- voluntariamente en medio de prueba.

En segundo lugar, se ha sostenido que la valoración del silencio parcial se derivaría de la existencia de una máxima de la experiencia, de acuerdo con ello, en determinadas situaciones el imputado "debería hablar, como forma de acreditar su inocencia"; su silencio parcial sería entonces equivalente a una confesión tácita ${ }^{56}$.

Por último, se ha argumentado que el silencio parcial del imputado debe ser entendido como parte integrante de un todo; como componente de una "unidad normativa" conformada por este en conjunto con la declaración parcial ${ }^{57}$ y que como tal debe ser íntegramente valorada por el juez ${ }^{58}$. En este sentido, los posibles vacíos en la declaración corresponderían a "componentes negativos" de la misma, susceptibles en todo caso de apreciación por parte del tribunal ${ }^{59}$. Entendidos declaración y silencio normativamente como un todo, sería desde un punto de vista psicológico imposible para el juez al momento de fundamentar su razonamiento ignorar los vacíos contenidos en la declaración del imputado, y separar con ello en su razonamiento declaración de silencio ${ }^{60}$.

Para otro sector de la doctrina mayoritaria ${ }^{61}$ el silencio parcial, si bien susceptible de apreciación por parte del tribunal (independiente de su justificación), no debe necesariamente ser valorado como un indicio en perjuicio del imputado. Una valoración en tal sentido solo resultará posible en aquellos casos en los que el silencio parcial sea

§25, Rdn. 33; RüPING, H., “Zur Mitwirkungspflicht des Beschuldigten und Angeklagten”, en JR 1974, p. 138; SchlüChter, E., Das Strafverfahren. 2. Ed., Heymanns, Köln y otros, 1983, Rdn. 467; VolK, K., “Anmerkung zum Urteil des BGH v. 26.10.1983-3 StR 251/83 (LG Duisburg)”, en NStZ 1984, p. 378.

${ }^{55}$ RüpING, H., “Zur Mitwirkungspflicht des Beschuldigten und Angeklagten”, en JR 1974, p. 138; SChlüchter, E., Das Strafverfahren. 2. Ed., Heymanns, Köln y otros, 1983, Rdn. 467. En la jurisprudencia: BGHSt 20, 298, 300; 32, 140 (145); BGH NStZ 2000, 495.

${ }^{56}$ GüNTHer, H., "Strafrechtliche Beweiswürdigung und schweigender Angeklagter”, en JR 1978, p. 93. Contra: Meyer, K., “Anmerkung zum Urteil des BGH 4. StS v. 3.12.65-4 StR 573/65”, en JR 1966, p. 352.

${ }^{57}$ RüpING, H., "Zur Mitwirkungspflicht des Beschuldigten und Angeklagten”, en JR 1974, p. 138; Wessels, J., "Schweigen und Leugnen im Strafverfahren”, en JuS 1966, p. 172. En la jurisprudencia: BGH NStZ 2000, 495.

58 RiEß, P., "Die Vernehmung des Beschuldigten im Strafprozeß”, en JA 1980, p. 295; Wessels, J., "Schweigen und Leugnen im Strafverfahren", en JuS 1966, p. 172. En la jurisprudencia: OLG Hamm NJW 1974, 1881.

59 Wessels, J., “Schweigen und Leugnen im Strafverfahren”, en JuS 1966, p. 172. En la jurisprudencia: BGH NStZ 2000, 495; BGH JR 2003, 166.

${ }^{60}$ Rieß, P., “Die Vernehmung des Beschuldigten im Strafprozeß”, en JA 1980, p. 295.

61 Löwe-Rosenberg: Die Strafprozeßordnung und das Gerichtsverfassungsgesetz. Großkommentar, Becker/Erb/Esser/Graalmann-Scheerer/Hilger/Ignor (coord.), de Gruyter, Berlin y otros, IV Tomo: $\$ § 112-150,26$. Ed., 2007, Gle $\beta$ \$136 Rdn. 38; Meyer, K., “Anmerkung zum Urteil des BGH 4. StS v. 3.12.65-4 StR 573/65”, en JR 1966, p. 352; Meyer-Gossner, L./SChMitT, B., Strafprozessordnung: Gerichtsverfassungsgesetz, Nebengesetze und ergänzende Bestimmungen. 58. Ed., Beck, München, 2015, §261, Rdn. 17. En la jurisprudencia BGH JR 2003, 166. 
atribuible a circunstancias específicas que permitan asignarle dicho valor. Por el contrario, cuando el silencio parcial sea atribuible a motivos puntuales que lleven a rechazar dicha valoración, deberá el juez abstenerse de apreciar el silencio parcial en perjuicio del imputado.

En concreto, de acuerdo con dicha opinión, el silencio parcial solo podrá considerarse como un indicio contra el imputado cuando una declaración respecto de los puntos omitidos pueda ser considerada - de acuerdo con las circunstancias concretas del caso- como "esperable", o bien cuando resulte lógico inferir que ante una pregunta determinada un imputado inocente hubiese optado por defenderse verbalmente ${ }^{62}$. Conforme con esta postura, una valoración del silencio parcial en perjuicio del imputado será posible por ejemplo en aquellos casos en los que el imputado intempestivamente calla al ser consultado respecto del lugar que se encontraba al momento de los hechos ${ }^{63}$.

Por el contrario, de acuerdo con dicha opinión, existirían otras situaciones en las que la experiencia impediría desprender del silencio parcial del imputado indicios de responsabilidad. Ello sucedería por ejemplo respecto del imputado que al comenzar su declaración ha declinado expresamente efectuar declaraciones respecto de uno o más puntos; cuando el silencio parcial obedezca a problemas de memoria, o bien cuando tras un largo interrogatorio el imputado decide no responder más preguntas aduciendo una falta de credibilidad por parte del tribunal ${ }^{64}$.

En contra de dicha postura mayoritaria, un sector importante de la doctrina ${ }^{65}$ ha sostenido -acertadamente- que el silencio parcial del imputado no puede ser objeto de valoración alguna por parte del tribunal. Dicha prohibición se desprende -al igual como sucede respecto del silencio total y temporal- del principio de no autoincriminación ${ }^{66}$.

${ }^{62}$ Löwe-Rosenberg: Die Strafprozeßordnung und das Gerichtsverfassungsgesetz. Großkommentar, Becker/Erb/Esser/Graalmann-Scheerer/Hilger/Ignor (coord.), de Gruyter, Berlin y otros, IV Tomo: $\S 112-$ 150, 26. Ed., 2007, Gleß \$136 Rdn. 38.

63 Löwe-Rosenberg: Die Strafprozeßordnung und das Gerichtsverfassungsgesetz. Großkommentar, Becker/Erb/Esser/Graalmann-Scheerer/Hilger/Ignor (coord.), de Gruyter, Berlin y otros, IV Tomo: $\S \S 112-$ 150, 26. Ed., 2007, Gleß \$136 Rdn. 38; Meyer, K., “Anmerkung zum Urteil des BGH 4. StS v. 3.12.65-4 StR 573/65”, en JR 1966, pp. 352 s.

${ }^{64}$ Löwe-Rosenberg: Die Strafprozeßordnung und das Gerichtsverfassungsgesetz. Großkommentar, Becker/Erb/Esser/Graalmann-Scheerer/Hilger/Ignor (coord.), de Gruyter, Berlin y otros, IV Tomo: $\S \S 112-$ 150, 26. Ed., 2007, Gleß $\$ 136$ Rdn. 38.

${ }^{65}$ Aselmann, M., “Anmerkung zum Beschluß des BGH v. 3.5.2000-1 StR 125/00”, en JR 2001, p. 81; Eisenberg, U., Beweisrecht der StPO: Spezialkommentar, 9. Ed., Beck, München, 2015, Rdn. 907 a ss; Hammerstein, G., "Sachaufklärung durch inquisitorische Vernehmung des Angeklagten", en: KürZINGER, J./Müller, E. (coord.), Festschrift für Wolf Middendorff zum 70. Geburtstag, Bielefeld, 1986, pp. 114 s; MiebaCH, K., "Der teilschweige Angeklagte - materiell-rechtliche und prozessuale Fragen anhand der BGHRechtsprechung”, en NStZ 2000, p. 236; SK-StPO: Systematischer Kommentar zur Strafprozessordnung. Mit GVG und EMRK, Wolter (coord.). Tomo II: \$\$94-136a StPO, 5. Ed., Heymanns, Köln, 2016, Rogall $\$ 133$ Rdn. 206 ss; Schneider, H., "Die strafprozessuale Beweiswürdigung des Schweigens von Beschuldigten und angehörigen Zeugen”, en JURA 1990, p. 579.

66 SK-StPO: Systematischer Kommentar zur Strafprozessordnung. Mit GVG und EMRK, Wolter (coord.). Tomo II: §\$94-136a StPO, 5. Ed., Heymanns, Köln, 2016, Rogall §133, Rdn. 209; Rogall, K., Der Beschuldigte als Beweismittel gegen sich selbst: ein Beitrag zur Geltung des Satzes "Nemo tenetur seipsum 
En cuanto garantía de carácter indivisible ${ }^{67}$, el nemo tenetur le confiere al imputado plena libertad de elegir la forma y oportunidad de prestar declaración o bien guardar silencio durante el transcurso del procedimiento ${ }^{68}$. En caso de aceptar una valoración del silencio parcial no se permitiría al imputado determinar los límites y alcances de su declaración: el libre ejercicio y vigencia de la garantía mencionada quedaría entonces en entredicho ${ }^{69}$.

Igualmente, si -en concordancia con la doctrina y jurisprudencia mayoritariaconsideramos que el silencio total y temporal del imputado no pueden ser objeto de valoración, resulta necesario rechazar lo propio respecto del silencio parcial: el imputado solo se convierte en medio de prueba respecto de lo declarado, mas no de lo que calla ${ }^{70}$. Como correlato de lo anterior, el imputado puede libremente y sin temor a experimentar un detrimento en su situación procesal, poner término a su declaración en cualquier momento $^{71}$; tan pronto decide callar dejará automáticamente de ser medio de prueba ${ }^{72}$.

Sin perjuicio de los fundamentos recién expuestos, existen motivos adicionales que permiten desestimar los argumentos esgrimidos por la doctrina y jurisprudencia mayoritaria en Alemania para justificar la valoración del silencio parcial del imputado.

En primer lugar, el silencio no puede en caso alguno ser interpretado como componente negativo de una declaración. Así como sucede respecto de quien calla solo en una declaración específica, en el caso del silencio parcial, silencio y declaración no pueden incluirse dentro de una misma categoría normativa ${ }^{73}$ :

prodere” im Strafprozeß. Duncker \& Humblot, Berlin, 1977, p. 252 ss; Schneider, H., "Die strafprozessuale Beweiswürdigung des Schweigens von Beschuldigten und angehörigen Zeugen”, en JURA 1990, p. 579.

${ }^{67}$ SK-StPO: Systematischer Kommentar zur Strafprozessordnung. Mit GVG und EMRK, Wolter (coord.). Tomo II: §§94-136a StPO, 5. Ed., Heymanns, Köln, 2016, Rogall §133, Rdn. 209.

68 Arndt, A., "Umwelt und Recht", en NJW 1966, p. 870; Aselmann, M., "Anmerkung zum Beschluß des BGH v. 3.5.2000-1 StR 125/00”, en JR 2001, p. 81; PARK, T., "Die prozessuale Verwertbarkeit verschiedener Formen der Beschuldigteneinlassung im Strafverfahren”, en StV 2001, p. 591; RogaLl, K., Der Beschuldigte als Beweismittel gegen sich selbst: ein Beitrag zur Geltung des Satzes "Nemo tenetur seipsum prodere" im Strafprozeß. Duncker \& Humblot, Berlin, 1977, p. 252; SK-StPO: Systematischer Kommentar zur Strafprozessordnung. Mit GVG und EMRK, Wolter (coord.). Tomo II: §§94-136a StPO, 5. Ed., Heymanns, Köln, 2016, Rogall §133, Rdn. 206; Stree, W., "Schweigen des Beschuldigten im Strafverfahren”, en JZ 1966, p. 599. En la jurisprudencia: OLG Düsseldorf StV 1983, 450.

${ }^{69}$ Fezer, Strafprozeßrecht. 2. Ed., Beck, München, 1995, p. 233; PARK, T., "Die prozessuale Verwertbarkeit verschiedener Formen der Beschuldigteneinlassung im Strafverfahren”, en StV 2001, p. 591; RoGALL, K., “Anmerkung zum Urteil des BGH v. 26.3.1992-5 StR 122/92 (BGHSt 38, 302)", en JR 1993, p. 381; SCHNEIDER, H., "Die strafprozessuale Beweiswürdigung des Schweigens von Beschuldigten und angehörigen Zeugen”, en JURA 1990, p. 579.

${ }^{70}$ Aselmann, M., “Anmerkung zum Beschluß des BGH v. 3.5.2000-1 StR 125/00”, en JR 2001, p. 81.

${ }^{71}$ EisenberG, U., Beweisrecht der StPO: Spezialkommentar, 9. Ed., Beck, München, 2015, Rdn. 907a; Rogall, Der Beschuldigte als Beweismittel gegen sich selbst: ein Beitrag zur Geltung des Satzes "Nemo tenetur seipsum prodere” im Strafprozeß. Duncker \& Humblot, Berlin, 1977, p. 252.

72 Stree, W., “Schweigen des Beschuldigten im Strafverfahren”, en JZ 1966, p. 598.

73 SK-StPO: Systematischer Kommentar zur Strafprozessordnung. Mit GVG und EMRK, Wolter (coord.). Tomo II: §§94-136a StPO, 5. Ed., Heymanns, Köln, 2016, Rogall §133, Rdn. 208; RogaLl, K., Der Beschuldigte als Beweismittel gegen sich selbst: ein Beitrag zur Geltung des Satzes "Nemo tenetur seipsum 
ambos son actos contrapuestos que no pueden ser lógicamente considerados de manera global $^{74}$.

Asimismo, si resultase posible incluir el silencio parcial como parte integrante de una supuesta unidad normativa en conjunto con la declaración parcial, debiese considerarse igualmente al silencio temporal en conjunto con la declaración efectivamente prestada, posibilitando su valoración ${ }^{75}$. Lo anterior -como vimos- ha sido rechazado unánimemente por la doctrina y la jurisprudencia.

Por otro lado, como se sostuvo supra, otorgar un valor probatorio determinado al silencio parcial del acusado supondría construir una máxima de la experiencia, basada en la interpretación meramente especulativa de las razones que conducen al silencio del imputado, cuyos presupuestos materiales resultan difícilmente justificables ${ }^{76}$. Como se mencionó, la indagación de los motivos que llevan a un imputado a callar constituye una materia que excede las facultades del juez en materia penal.

Por último, considerar el rechazo a valorar el silencio parcial del imputado como una transgresión al principio de libre valoración de la prueba resulta errado. Dicho argumento desconoce que la averiguación de la verdad no constituye un valor absoluto en el proceso penal, sino que se encuentra sujeto a límites ${ }^{77}$. En efecto, todo sistema procesal penal en un Estado democrático de Derecho se constituye a partir de dos intereses estatales contrapuestos: por un lado, el deber de instar por una eficiente persecución $^{78} \mathrm{y}$, por otro, el debido respeto de las garantías del imputado en el proceso penal. En este sentido, la jurisprudencia reiterada del $\mathrm{BGH}$ y del $\mathrm{BVerfG}^{79}$ ha señalado

prodere” im Strafprozeß. Duncker \& Humblot, Berlin, 1977, p. 253; RüPING, H., "Zur Mitwirkungspflicht des Beschuldigten und Angeklagten", en $J R$ 1974, p. 138; STREe, W., "Schweigen des Beschuldigten im Strafverfahren”, en $J Z 1966$, pp. 598 s.

${ }^{74}$ Rogall, K., “Anmerkung zum Urteil des BGH v. 26.3.1992-5 StR 122/92 (BGHSt 38, 302)”, en JR 1993, p. 381; SCHNEIDER, H., "Die strafprozessuale Beweiswürdigung des Schweigens von Beschuldigten und angehörigen Zeugen”, en JURA 1990, p. 579; STREE, W., "Schweigen des Beschuldigten im Strafverfahren”, en $J Z 1966$, pp. 598 s.

75 SK-StPO: Systematischer Kommentar zur Strafprozessordnung. Mit GVG und EMRK, Wolter (coord.). Tomo II: §\$94-136a StPO, 5. Ed., Heymanns, Köln, 2016, Rogall §133 Rdn. 208.

${ }^{76}$ En este sentido: Aselmann, M., “Anmerkung zum Beschluß des BGH v. 3.5.2000-1 StR 125/00”, en $J R 2001$, p. 81.

77 JäGER, C., “Anmerkung zum Urteil des BGH v. 18.04.2002-3 StR 370/01”, en JR 2003, p. 166; SK-StPO: Systematischer Kommentar zur Strafprozessordnung. Mit GVG und EMRK, Wolter (coord.). Tomo II: §§94-136a StPO, 5. Ed., Heymanns, Köln, 2016, Rogall §133 Rdn. 208.

${ }^{78}$ BVerfGE 130, 1 (28); 122, 248 (272, f.); 107, 104 (118, f.); 80, 367 (375); 77, 65 (76); 74, 257 (262); 51, 324 (343, f.); 47, 239 (250); 46, $214(222) ; 44,353(374) ; 41,246(250) ; 39,156(163) ; 38,312$ (321); 38, 105 (116); 36, 174 (186); 34, 238 (248); 33, 367 (383); 29, 183 (194); 20, $144(147) ; 20,45$ (49); 19, 342 (347); BVerfG NJW 2009, 907 (909); BVerfG NStZ 1996, 45. Vgl. BGHSt; 47, 172 (179); 42, 170 (174); 38, $214(220) ; 29,23(25)$.

${ }^{79}$ BGHSt 14, 358 (365); 31, 304 (309); 38, 214 (220); 38, 372 (374); 51, 285 (290); 58, 301 (309). BVerfG NJW 2011, 2783 (2784). Al respecto: Roxin, C., "Die Rechtsprechung des Bundesgerichtshofs zum Strafverfahrensrecht - Ein Rückblick auf 40 Jahre”, en Roxin, C./JAuernig, O. (coord.), 40 Jahre Bundesgerichtshof: Festveranstaltung am 1. Oktober 1990 mit Ansprache des Präsidenten des Bundesgerichtshofes; Vorträge, Heidelberg, 1991, pp. 78 ss. 
consistentemente que la verdad en el proceso penal no es un valor que pueda ser alcanzado a cualquier precio. Ejemplo paradigmático a este respecto lo constitye el reconocimiento por parte de la jurisprudencia alemana de las llamadas "prohibiciones probatorias", en las que -a partir de la concurrencia o ausencia de distintos parámetros normativos referidos al caso concreto- resulta posible excluir del ámbito de la valoración de la prueba (con el eventual perjuicio para la búsqueda de la verdad procesal) determinados medios de prueba atendido su origen ${ }^{80}$, o bien la vulneración de ciertas garantías establecidas en la Constitución que su eventual valoración generaría ${ }^{81}$.

En el caso del silencio del imputado es igualmente posible constatar la presencia de límites a la búsqueda de la verdad. Precisamente, el ejercicio y resguardo del derecho a guardar silencio constituye una barrera infranqueable para el tribunal; su respeto constituye un componente esencial del proceso penal que condiciona finalmente su legitimidad.

La prohibición de valorar el silencio parcial del imputado desde luego no se extiende a lo efectivamente declarado; sus afirmaciones se encuentran por cierto incluidas dentro de la valoración de la prueba ${ }^{82}$.

\section{CONSAgRACIÓN LEgAL DEL DERECHO A GUARDAR SILENCIO EN EL PROCESO PENAL CHILENO}

Como se señaló anteriormente, en Chile el derecho del imputado a guardar silencio se encuentra expresamente consagrado a nivel legal. En primer lugar, el art. 93 letra g) del CPP reconoce el derecho del imputado a guardar silencio, o en caso de consentir en prestar declaración, a no bacerlo bajo juramento. A continuación, la misma disposición establece que al momento en el que el imputado presta la primera declaración ante el fiscal o la policía, deberá señalársele que (t)iene derecho a guardar silencio. El ejercicio de este derecho no le ocasionará ninguna consecuencia legal adversa; sin embargo, si renuncia a él, todo lo que manifieste podrá ser usado en su contra.

${ }^{80}$ BGH NStZ-RR 2014, 318 (319) ; BGHSt 58, 301 (307, f.); 58, 84 (96); 56, 127 (132, 135); 52, 110 (116); 51, 285 (290); 47, 172 (179); 44, 243 (249); 42, 170 (172, 174); 42, 139 (157); 42, 15 (21); 38, 372 (373 ff.); 38, 214 (219, ff.); 37, 30 (32); 35, 32 (34); 34, 397 (401); 31, 304 (307); 27, 355 (357); 24, 125 (130, ff.); 19, 325 (329); BGH NJW 2003, 2034 (2035); Vgl. Dalakouras, T., Beweisverbote bezüglich der Achtung der Intimsphäre: unter besonderer Berücksichtigung der Grundrechtsproblematik sowie des griechischen Rechts. Duncker \& Humblot, Berlin, 1988, p. 125; JAHN, M., "Beweiserhebungs- und Beweisverwertungsverbote im Spannungsfeld zwischen den Garantien des Rechtsstaates und der effektiven Bekämpfung von Kriminalität und Terrorismus”, en: Juristentages, Ständigen Deputation des deutschen (coord.), Verhandlungen des Siebenundsechzigsten Deutschen Juristentages: Erfurt 2008 Band I Gutachten, München, 2008, C 46; Roxin, C., "Die Rechtsprechung des Bundesgerichtshofs zum Strafverfahrensrecht Ein Rückblick auf 40 Jahre”, en Roxin, C./JAuerNig, O. (coord.), 40 Jabre Bundesgerichtshof: Festveranstaltung am 1. Oktober 1990 mit Ansprache des Präsidenten des Bundesgerichtshofes; Vorträge, Heidelberg, 1991, p. 70.

${ }^{81}$ BVerfGE 34, 238 (245, ff). Vgl. BVerfGE 80, 367 (373 ff.).

${ }^{82}$ Rogall, K., Der Beschuldigte als Beweismittel gegen sich selbst: ein Beitrag zur Geltung des Satzes "Nemo tenetur seipsum prodere" im Strafprozeß. Duncker \& Humblot, Berlin, 1977, p. 252. 
El alcance de la referida disposición debe ser entendido en concordancia con la concepción de la declaración del imputado como medio de defensa, establecida en el art. $98 \mathrm{CPP}$, así como con diversas disposiciones que establecen el carácter voluntario de la declaración del imputado (Arts. 91, 194, 268 y 326 CPP).

A nivel supralegal, sin embargo, el panorama es menos claro, existiendo discrepancias entre la regulación establecida en Tratados Internacionales ratificados por Chile y lo señalado por la Constitución Política.

En primer término, la Convención Americana de DD.HH. reconoce en su art. 8.2. letra g), a toda persona inculpada por un delito el derecho a no declarar contra sí mismo ni a declararse culpable. Igualmente, el artículo 14.3 letra g) del Pacto Internacional de Derechos Civiles y Políticos establece que durante el proceso, toda persona acusada de un delito tendrá derecho a no ser obligada a declarar contra sí misma ni a confesarse culpable.

En contraposición a los Tratados Internacionales referidos, la Constitución Política de la República (CPR) no reconoce expresamente el derecho del imputado a guardar silencio. En sintonía con la regulación legal vigente hasta 1989, el texto constitucional se limita a consagrar (Art. 19 Nr. 7 letra f) CPR) la imposibilidad de obligar al imputado o acusado a que declare bajo juramento sobre hecho propio. De acuerdo con el tímido tenor literal de la Carta Fundamental nada impediría, por ejemplo, obligar a una persona a declarar, siempre y cuando dicha acción no se lleve a cabo bajo juramento.

La regulación a nivel constitucional posee entonces un alcance limitado, contrapuesto no solo a la regulación supralegal consagrada en los Tratados Internacionales referidos, sino además a lo establecido al respecto en el CPP. De lege ferenda resulta aconsejable solucionar dicha discrepancia, armonizando el texto constitucional con la legislación vigente.

\section{El SILENCIO TOTAL DEL IMPUTAdo EN EL DERECHO CHILENO}

En el Derecho chileno no es posible otorgar valor alguno al silencio total del imputado ${ }^{83}$.

Dicha conclusión se desprende fundamentalmente de lo dispuesto en el ya mencionado art. 93 letra g) CPP, disposición que prohíbe expresamente derivar consecuencias adversas para el imputado del ejercicio de su derecho a guardar silencio. Dicha prohibición deberá ser informada al imputado por parte del funcionario respectivo, antes de prestar su primera declaración.

Desde luego, la posibilidad de valorar el silencio del imputado incluye la de hacerlo de manera desfavorable a sus intereses, esto es -paradigmáticamente-como un indicio en su contra. De este modo, en caso que aceptásemos dicha posibilidad se estaría vulnerando

${ }^{83}$ En este sentido igualmente: Horvitz Lennon M.I./López Masle, J., Derecho procesal penal chileno, Tomo II, Ed. Jurídica, Santiago, 2004, p. 83; Chahuán Sarras, S., Manual del nuevo procedimiento penal. 4 a Ed., LegalPublishing Chile, Santiago, 2009, p. 311. 
el mandato legal que impide derivar consecuencias legales adversas del ejercicio del derecho a guardar silencio, quedando la vigencia de la referida norma en entredicho.

Por otro lado, la valoración del silencio ejercido por un imputado informado debidamente de su derecho en los términos ya referidos tendría un origen espurio. Ella se originaría no a partir de una decisión consciente del imputado, sino más bien a base de un verdadero engaño inducido por parte de un funcionario público respecto de los alcances de un derecho. La imposibilidad de derivar consecuencias negativas del silencio expresada por el legislador no solo sería en estos casos letra muerta, sino que -lo que es aún más grave- constituiría un verdadero "anzuelo" para el imputado a efectos de incentivar un silencio cuyas reales consecuencias resultaban para él del todo desconocidas. Generar tal posibilidad de error en el imputado a efectos de lograr una consecuencia procesal determinada resulta incompatible con el principio de buena fe y el debido proceso (Art. $19 \mathrm{Nr} .7^{\circ} \mathrm{CPR}$ ).

En segundo lugar, negar valor al silencio del imputado resulta necesario, con el fin de reafirmar la vigencia de la garantía nemo tenetur se ipsum accusare ${ }^{84}$. Al respecto, como se señaló pormenorizadamente respecto del derecho alemán, permitir desprender consecuencias negativas del ejercicio del derecho a guardar silencio, transformaría dicha garantía finalmente en una fuente de perjuicios para su titular.

Por último, como se señaló anteriormente, las razones que llevan al imputado a guardar silencio obedecen a motivaciones internas, cuya determinación excede -como corolario del derecho a guardar silencio- el alcance del tribunal. Al resultar imposible reconducir los diversos motivos que llevan a un imputado a no declarar a un motivo de contenido inequívoco, atribuir arbitrariamente un significado a priori a dicha actitud constituirá simplemente una mera especulación, incapaz de generar convicción alguna ${ }^{85}$.

En concordancia con la postura aquí asumida, sostuvo la Corte Suprema en sentencia dictada en causa Ingreso Nr. 6247-14 (Considerando 20) que (...) el imputado no tiene ni la carga ni el deber de probar nada, menos su inocencia, aunque, sin embargo, siempre le asiste el derecho de aportar toda la prueba que estime pertinente en aval de su teoría del caso. Por lo mismo su indiferencia no le puede acarrear ningún perjuicio. (...).

(Considerando $22^{\circ}$ ) Que es efectivo que el que guarda silencio simplemente no dice nada y que de su silencio no cabe extraer conclusión alguna, pues su pasividad solo puede significar expresión del ejercicio de su derecho a obrar de tal forma, pues no tiene deber jurídico -ni moralde colaborar con la persecución penal dirigida en su contra, siendo, en consecuencia, obligación de la Fiscalía remover la presunción de inocencia que le asiste al imputado.

${ }^{84}$ En este sentido igualmente: Horvitz Lennon M.I./López Masle, J., Derecho procesal penal chileno, Tomo II, Ed. Jurídica, Santiago, 2004, p. 83; Maturana Miquel, C./Montero López, R., Derecho Procesal Penal, Tomo II, LegalPublishing Chile, Santiago, 2012, p. 981.

${ }^{85}$ En este sentido igualmente: Horvitz Lennon, M.I./López Masle, J. Derecho procesal penal chileno, Tomo II, Ed. Jurídica, Santiago, 2004, p. 84. 
La opinión contraria ha sido sustentada por Riego ${ }^{86}$. Para dicho autor, la valoración del silencio no solo resultaría legítima, sino que constituiría una verdadera obligación para el juez. Dicha interpretación se derivaría para el autor, en primer término, a partir de la existencia de un derecho a declarar, el que permitiría al juez legítimamente efectuar deducciones que refuerzan la credibilidad de la versión acusatoria ${ }^{87}$. Contrario sensu a partir de un análisis del contexto en que se produce el silencio del acusado y de las circunstancias que rodean el hecho, sería posible para el juez arribar a conclusiones que permitirían utilizar el silencio en contra del imputado ${ }^{88}$.

Lo sostenido por Riego contradice abiertamente la regulación legal y supralegal actualmente vigente. En efecto, una valoración del silencio del imputado transgrede el tenor literal de los mencionados Art. 93 letra g) CPP; 8.2. de la Convención Americana de DD.HH. y 14.3 letra g) del Pacto Internacional de Derechos Civiles y Políticos, generando consecuencias negativas a partir del ejercicio de un derecho cuyo reconocimiento resulta indiscutido. La postura de Riego convierte el derecho a guardar silencio en una eventual fuente de perjuicio para el imputado, poniendo su vigencia y en definitiva su condición de garantía en entredicho.

Por otra parte, el argumento de Riego peca de falaz: de la existencia de un "derecho a declarar", del que -desde luego- pueden desprenderse consecuencias negativas para el imputado, no se desprende que dichas conclusiones sean extrapolables a la acción inversa, esto es, guardar silencio. Silencio y declaración son, desde un punto de vista procesal, hechos incomparables. Si bien quien decide declarar-por expreso mandato del art. 93 letra g) CPP- lo hace a sabiendas de que su declaración podría ser utilizada en su contra (como también a su favor), quien calla, precisamente lo hace bajo el entendido que su actitud no le generará perjuicio -ni beneficio- alguno. Declarar conlleva un riesgo procesal concreto que el imputado decide libremente asumir; guardar silencio por el contrario revela precisamente la intención del imputado de evitar dicho riesgo.

${ }^{86}$ Riego, C., La declaración del imputado en el juicio oral. Sin página indicada. http://w1.cejamericas. org/index.php/biblioteca/biblioteca-virtual/doc_view/1973-la-declaraci\%C3\%B3n-del-imputado-en-el-juiciooral.html

${ }^{87}$ Riego, C., La declaración del imputado en el juicio oral. Sin página indicada. http://w1.cejamericas. org/index.php/biblioteca/biblioteca-virtual/doc_view/1973-la-declaraci\%C3\%B3n-del-imputado-en-el-juiciooral.html

${ }^{88}$ En la jurisprudencia no es posible encontrar sentencia alguna emitida por los tribunales superiores que sostenga dicha postura. Sin perjuicio de lo anterior, una primera aproximación a la sentencia dictada por la Corte de Apelaciones de Concepción en autos Rol No 531-2005 (Reforma Procesal Penal) podría llevar a la conclusión contraria. En dicho fallo sostuvo la Corte (Cons. $9^{\circ}$ ): (...) es efectivo que el guardar silencio constituye un derecho inalienable del imputado (...) pero lo cierto es que si en el presente proceso la eventual justificación suficiente no pudo ser probada por la Fiscalía, ello arranca esencialmente de que nada aportó el condenado en su defensa en este aspecto. Si el imputado prefirió no decir nada en el proceso, entonces deberá estarse tanto a lo favorable como a lo perjudicial de la opción asumida (...). La referencia efectuada por la Corte en este caso, referida a lo "favorable como desfavorable" del silencio, debe sin embargo entenderse desde la óptica de estrategia de defensa, esto es, entendiendo al silencio del imputado como una alternativa que merma las posibilidades fácticas del imputado de controvertir prueba de cargo y generar una duda razonable en el tribunal, mas no respecto de una supuesta valoración del silencio. 


\section{El SILENCIO TEMPORAL Y EL SILENCIO PARCIAL} EN EL DERECHO CHILENO

Tanto el silencio temporal como el silencio parcial han sido escasamente estudiados por parte de la doctrina chilena.

Una primera aproximación al problema se encuentra en el citado trabajo de Riego, quien tras analizar someramente dichas constelaciones se inclina en ambos casos por admitir su valoración por parte del tribunal ${ }^{89}$. En lo referente al silencio temporal del acusado, sostiene dicho autor que el silencio en las etapas previas debilita las declaraciones prestadas en el juicio y por lo tanto es un hecho relevante relativo a la credibilidad del imputa$d 0^{90}$. Por su parte, respecto del silencio parcial del acusado, el mencionado autor señala someramente que el silencio es más significativo frente a preguntas específicas, sin indicar las razones para arribar a tal conclusión.

En idéntico sentido ha sostenido Chahuán -siguiendo expresamente a la jurisprudencia mayoritaria alemana- que el silencio parcial puede ser objeto de valoración por parte del juez, pues en estos casos el imputado se convierte él mismo, por libre decisión, en un medio de prueba y, con ello, se somete a la libre valoración de la prueba ${ }^{91}$. Excluido de la valoración del tribunal se encuentra sin embargo - de acuerdo con el autor-el silencio de aquel imputado acusado por diversos hechos, y que decide declarar respecto de algunos, guardando silencio respecto de otros ${ }^{92}$.

En el derecho chileno no resulta procedente valorar el silencio parcial ni el silencio temporal del imputado. En efecto, como sostiene correctamente un sector de la doctrina alemana ya analizado ${ }^{93}$, el derecho a guardar silencio corresponde -también en el derecho chileno- a una garantía de carácter indivisible que puede ser ejercida en la forma y oportunidad que su titular arbitrariamente determine. En este sentido, la libertad que le asiste al imputado de declarar en una etapa del procedimiento y guardar silencio en otra, o bien de guardar silencio en una misma declaración frente a determinadas preguntas concretas, constituyen elementos inherentes al ejercicio del derecho referido.

${ }^{89}$ RiEgo, C., La declaración del imputado en el juicio oral. Sin página indicada. http://w1.cejamericas. org/index.php/biblioteca/biblioteca-virtual/doc_view/1973-la-declaraci\%C3\%B3n-del-imputado-en-el-juiciooral.html

${ }^{90}$ Riego, C., La declaración del imputado en el juicio oral. Sin página indicada. http://w1.cejamericas. org/index.php/biblioteca/biblioteca-virtual/doc_view/1973-la-declaraci\%C3\%B3n-del-imputado-en-el-juiciooral.html

${ }^{91}$ Chahuán Sarras, S., Manual del nuevo procedimiento penal. 4a Ed., LegalPublishing Chile, Santiago, 2009 , p. 311.

${ }^{92}$ Chahuán Sarras, S., Manual del nuevo procedimiento penal. 4a Ed., LegalPublishing Chile, Santiago, 2009, p. 311.

93 KüHL, K., "Freie Beweiswürdigung des Schweigens des Angeklagten und der Untersuchungsweigerung eines angehörigen Zeugen-BGHSt 32, 140”, en JuS 1986, p. 120; RogaLl, K., Der Beschuldigte als Beweismittel gegen sich selbst: ein Beitrag zur Geltung des Satzes "Nemo tenetur seipsum prodere" im Strafprozeß. Duncker \& Humblot, Berlin, 1977, p. 254. 
El ejercicio total, parcial o temporal del derecho a guardar silencio no puede restringirse argumentando una supuesta preclusión del mismo fundada por ejemplo en declaraciones anteriores o parciales. Los alcances de la renuncia al derecho solo pueden alcanzar lo efectivamente declarado por el imputado, mas no su silencio. El silencio parcial o temporal no constituye entonces un "elemento negativo" de una declaración, sino por el contrario, una ausencia de la misma.

Por último, como sucede en el derecho alemán, la doctrina ${ }^{94}$ y la jurisprudencia mayoritaria ${ }^{95}$ en Chile se inclinan por admitir como testigos de oídas a funcionarios que presenciaron una declaración del imputado en la etapa de investigación, siempre y cuando la declaración haya sido prestada de manera libre e informada. Dicha posición nos parece acertada. Como mencionamos anteriormente, el derecho a guardar silencio del imputado no se ve vulnerado en caso de admitir las declaraciones de testigos de oídas a efectos de dar cuenta de una declaración previa; habiendo el imputado renunciado a su derecho a guardar silencio en un momento determinado del procedimiento, lo declarado en dicha oportunidad podrá ser incorporado indirectamente al juicio por otros medios de prueba.

\section{CONCLUSIONES}

El imputado que guarda silencio no se transforma asimismo en medio de prueba. El derecho a guardar silencio es uno e indivisible y en cuanto tal puede ser ejercido indistintamente por su titular de manera total, temporal o parcial. El silencio del imputado, sea cual sea la forma y oportunidad en la que es ejercido, se mantiene totalmente fuera del alcance de la valoración de la prueba. Como sostenía Eb. Schmidt, el ejercicio de un derecho consagrado a favor del imputado, como lo es el de guardar silencio, en caso alguno puede conducir a un detrimento de la posición jurídica de su titular ${ }^{96}$.

${ }^{94}$ Cfr. Dorn Garrido, C., "El testimonio de oídas y el privilegio de no autoincriminación”, en Revista de Derecho (Consejo de Defensa del Estado), 2003, p. 117; Horvitz Lennon, M.I./López Masle, J., Derecho procesal penal chileno, Tomo II, Ed. Jurídica, Santiago, 2004, p. 92; RIEGO, C., http://w1.cejamericas.org/ index.php/biblioteca/biblioteca-virtual/doc_view/1973-la-declaraci\%C3\%B3n-del-imputado-en-el-juicio-oral. html (sin página indicada); Tavolari Oliveros, R., Instituciones del nuevo proceso penal, Editorial Jurídica de Chile, Santiago, 2007, p. 169. En contra: Poblete Iturrate, O., "El interrogatorio policial autónomo y el derecho al silencio y a la no autoincriminación", en Sentencias destacadas. Anuario de jurisprudencia: una mirada desde la perspectiva de las políticas públicas / Libertad y Desarrollo, 2004, pp. 237 ss.

${ }^{95}$ Corte Suprema Ingreso No 922-2004; Corte de Apelaciones de Santiago, Ingresos Nr. 2474-2015 y 89-2006, Corte de Apelaciones de Chillán, Ingreso Nr. 208-12, Corte de Apelaciones de Rancagua, Ingreso $\mathrm{N}^{\circ}$ 98-2004. Una opinión distinta se encuentra en Corte de Apelaciones de Punta Arenas, Ingreso Nr. 112006 que rechaza la posibilidad de admitir la declaración de funcionarios presentes al momento en que se llevó a cabo la declaración.

96 Al respecto vid. SснміDT, E., "§261 StPO in der neueren höchstrichterlichen Rechtsprechung”, en $J Z 1970$, p. 341. 


\section{BiBLIOGRAFÍA}

Arndt, A., "Umwelt und Recht", en NJW 1966, pp. 869-872.

Aselmann, M., “Anmerkung zum Beschluß des BGH v. 3.5.2000-1 StR 125/00”, en JR 2001, pp. 80-82.

BeulKe, W., Strafprozessrecht. 12. Ed., Müller, Heidelberg y otros, 2012.

Chahuán Sarras, S., Manual del nuevo procedimiento penal. 4a Ed., LegalPublishing Chile, Santiago, 2009.

Correa, C. "Comentario Sentencia Ingreso No 18-2013, Corte de Apelaciones de Valparaíso, Infracción a las reglas reguladoras de la prueba", en Revista Chilena de Derecho y Ciencias Penales, Vol. II, 2013, No 2, pp. 185-194.

Dahs, H./LangKeIt, J., "Das Schweigerecht des Beschuldigten und seine Auskunftsverweigerung als "verdächtiger Zeuge", en NStZ 1993, pp. 213-216.

Dalakouras, T., Beweisverbote bezüglich der Achtung der Intimsphäre: unter besonderer Berücksichtigung der Grundrechtsproblematik sowie des griechischen Rechts. Duncker \& Humblot, Berlin, 1988.

Dorn Garrido, C., "El testimonio de oídas y el privilegio de no autoincriminación”, en Revista de Derecho (Consejo de Defensa del Estado), 2003, pp. 111-122.

EISEnberg, U., Beweisrecht der StPO: Spezialkommentar, 9. Ed., Beck, München, 2015.

FEZER, G., Strafprozeßrecht. 2. Ed., Beck, München, 1995.

Grünwald, G., Das Beweisrecht der Strafprozeßordnung, Nomos, Baden-Baden, 1993.

GüNTHER, H., "Strafrechtliche Beweiswürdigung und schweigender Angeklagter", en JR 1978, pp. 89-94.

Hammerstein, G., "Sachaufklärung durch inquisitorische Vernehmung des Angeklagten", en: Kürzinger, J./Müller, E. (coord.), Festschrift für Wolf Middendorff zum 70. Geburtstag, Bielefeld, 1986, pp. 111-116.

Horvitz Lennon, M.I./López Masle, J., Derecho procesal penal chileno, Tomo II, Ed. Jurídica, Santiago, 2004.

JÄGER, C., “Anmerkung zum Urteil des BGH v. 18.04.2002-3 StR 370/01”, en JR 2003, pp. 166-168.

JAHN, M., "Beweiserhebungs- und Beweisverwertungsverbote im Spannungsfeld zwischen den Garantien des Rechtsstaates und der effektiven Bekämpfung von Kriminalität und Terrorismus", en: Juristentages, Ständigen Deputation des deutschen (coord.), Verhandlungen des Siebenundsechzigsten Deutschen Juristentages: Erfurt 2008 Band I Gutachten, München, 2008 pp. C 1 ss.

Kasiske, P., "Die Selbstbelastungsfreiheit im Strafprozess", en JuS 2014, pp. 15-20.

KLeinknecht, T., “Anmerkung zur Urteil des BGH 5. StS v. 26.10.65-5 StR 415/65”, en JR 1966, pp. 270-271.

KÜHL, K., "Freie Beweiswürdigung des Schweigens des Angeklagten und der Untersuchungsweigerung eines angehörigen Zeugen - BGHSt 32, 140”, en JuS 1986, pp. 115-122.

Löwe-Rosenberg: Die Strafprozeßordnung und das Gerichtsverfassungsgesetz. Großkommentar, Becker/Erb/Esser/Graalmann-Scheerer/Hilger/Ignor (coord.), de Gruyter, Berlin y otros, IV Tomo: §§112-150, 26. Ed., 2007.

Maturana Miquel, C./Montero López, R., Derecho Procesal Penal. Tomo II, LegalPublishing Chile, Santiago, 2012.

Meyer, K., “Anmerkung zum Urteil des BGH 4. StS v. 3.12.65-4 StR 573/65”, en JR 1966, pp. 352-353. 
Meyer-Gossner, L./Schmitt, B., Strafprozessordnung: Gerichtsverfassungsgesetz, Nebengesetze und ergänzende Bestimmungen. 58. Ed., Beck, München, 2015.

Michaels, R. "The Functional Method of Comparative Law”, en Reimann/Zimmermann (coord.), The Oxford Handbook of Comparative Law, Oxford, 2012, pp. 1-32.

MiebaCH, K., "Der teilschweige Angeklagte - materiell-rechtliche und prozessuale Fragen anhand der BGH-Rechtsprechung”, en NStZ 2000, pp. 234-242.

Müller-Christmann, B., “Aktuelles Strafprozessrecht”, en JuS 2001, pp. 60-64.

Ostermeyer, H., "Der schweigende Beschuldigte”, en NJW 1967, pp. 915-917.

Paillás, E., Estudios de Derecho Probatorio, 2 ${ }^{\text {a }}$ Ed., Editorial Jurídica de Chile, 2002.

PARK, T., "Die prozessuale Verwertbarkeit verschiedener Formen der Beschuldigteneinlassung im Strafverfahren”, en $S t V$ 2001, pp. 589-595.

Pelchen, G., “Anmerkung zum Urteil des BGH v. 26.10.1983-3 StR 251/83 (BGHSt. 32, 140)", en $J R$ 1985, pp. 71-74.

Poblete Iturrate, O., "El interrogatorio policial autónomo y el derecho al silencio y a la no autoincriminación”, en Sentencias destacadas. Anuario de jurisprudencia: una mirada desde la perspectiva de las políticas públicas / Libertad y Desarrollo, 2004, pp. 237-254.

Ramírez Tagle, C., "Nemo Tenetur Se Ipsum. El Derecho a guardar silencio", en Ars Boni et Aequi 2007, pp. 65-80.

Ransiek, A./Winsel, A., "Die Selbstbelastung im Sinne des "nemo tenetur se ipsum accusare"Grundsatzes”, en GA 2015, pp. 620-638.

Riego, C., "La declaración del imputado en el Juicio Oral”, en http://w1.cejamericas.org/index. php/biblioteca/biblioteca-virtual/doc_view/1973-la-declaraci\%C3\%B3n-del-imputadoen-el-juicio-oral.html

Riess, P., "Die Vernehmung des Beschuldigten im Strafprozeß”, en JA 1980, pp. 293-301.

Rogall, K., “Anmerkung zum Urteil des BGH v. 26.3.1992-5 StR 122/92 (BGHSt 38, 302)”, en JR 1993, pp. 380-382.

Rogall, K., Der Beschuldigte als Beweismittel gegen sich selbst: ein Beitrag zur Geltung des Satzes "Nemo tenetur seipsum prodere” im Strafprozeß, Duncker \& Humblot, Berlin, 1977.

Roxin, C., "Die Rechtsprechung des Bundesgerichtshofs zum Strafverfahrensrecht - Ein Rückblick auf 40 Jahre”, en Roxin, C./Jauernig, O. (coord.), 40 Jahre Bundesgerichtshof: Festveranstaltung am 1. Oktober 1990 mit Ansprache des Präsidenten des Bundesgerichtshofes; Vorträge, Heidelberg, 1991, pp. 66-99.

Roxin, C./Schünemann, B., Strafverfabrensrecht: ein Studienbuch. 28. Ed., Beck. München, 2014.

RüPING, H., “Zur Mitwirkungspflicht des Beschuldigten und Angeklagten”, en JR 1974, pp. $135-140$.

SChlüChter, E., Das Strafverfabren. 2. Ed., Heymanns, Köln y otros, 1983.

SCHмIDT, E., "\$261 StPO in der neueren höchstrichterlichen Rechtsprechung”, en JZ 1970, pp. 337-343.

SCHNEIDER, H., "Die strafprozessuale Beweiswürdigung des Schweigens von Beschuldigten und angehörigen Zeugen”, en JURA 1990, pp. 572-582.

Stein, F., Das Private Wissen des Richters, C.L. Hirschfeld, Leipzig, 1893.

SK-SтPO: Systematischer Kommentar zur Strafprozessordnung. Mit GVG und EMRK, Wolter (coord.). Tomo II: $\$ \$ 94-136$ a StPO, 5. Ed., Heymanns, Köln, 2016.

STREE, W., "Schweigen des Beschuldigten im Strafverfahren”, en JZ 1966, pp. 593-600.

Tavolari Oliveros, R., Instituciones del nuevo proceso penal, Editorial Jurídica de Chile, Santiago, 2007.

VolK, K., “Anmerkung zum Urteil des BGH v. 26.10.1983-3 StR 251/83 (LG Duisburg)”, en NStZ 1984, pp. 377-378. 
Wessels, J., "Schweigen und Leugnen im Strafverfahren”, en JuS 1966, pp. 169-176.

WilenMANN, J., "El tratamiento del autofavorecimiento del imputado. sobre las consecuencias sustantivas del principio de no autoincriminación", en RDUCN vol.23 no.1 Coquimbo jun. 2016, pp. 111-139. 
